Jurnal DISASTRI (Pendidikan Bahasa dan Sastra Indonesia)

Volume 2, Nomor 1, Maret 2020| P-ISSN : 2716-4112 | E-ISSN: 2722-3329

\title{
FAKTOR PENYEBAB TERJADINYA INTERFERENSI BAHASA INDONESIA TUTURAN MAHASISWA THAILAND PADA PEMBELAJARAN PPL DASAR DI UNIVERSITAS HASYIM ASY'ARI
}

\author{
Siti Mariana Ulfa ${ }^{1}$ \\ Program Studi Pendidikan Bahasa dan Sastra Indonesia, Fakultas Ilmu Pendidikan, \\ Universitas Hasyim Asy'ari, Sitimariana0718@gmail.com \\ Udjang Pairin M. Basir ${ }^{2}$ \\ Pendidikan Bahasa dan Sastra Indonesia, Fakultas Bahasa dan Sastra, \\ Universitas Negeri Surabaya, udjangjw@unesa.ac.id \\ Yulianah Prihatin ${ }^{3}$ \\ Program Studi Pendidikan Bahasa dan Sastra Indonesia, Fakultas Ilmu Pendidikan, \\ Universitas Hasyim Asy'ari, yuliaana553@gmail.com
}

\begin{abstract}
Abstrak
Penelitian ini bertujuan untuk mengetahui faktor penyebab terjadinya interferensi Bahasa Indonesia yang terjadi pada mahasiswa Thailand saat praktik mata kuliah PPL di Universitas Hasyim Asy'ari. Metode penelitian ini menggunakan metode kualitatif dengan teknik pengumpulan data menggunakan teknik observasi, teknik merekam audio visual dengan menggunakan CCTV di ruang praktik, dan teknik mencatat. Untuk mendapatkan keabsahan data peneliti menggunakan triangulasi data, peningkatan penekunan dan pemeriksaan teman sejawat melalui diskusi. Adapun proses analisis datanya yaitu pengumpulan data, reduksi data, penyajian data, dan simpulan. Kebanyakan pada tuturan mahasiswa Thailand sering terjadi interferensi pada sistem fonologi, dimana mereka masih terbawa oleh bahasa pertama atau bahasa ibu (B1) yaitu bahasa Melayu. Interferensi pada sistem morfologi serta pada sistem sintaksis dapat terjadi karena mereka kurang memahami kosa kata dan susunan kalimat pada bahasa Indonesia yang baik dan benar.
\end{abstract}

Kata Kunci: Penyebab, Interferensi

\begin{abstract}
This study aims to determine the factors that cause Indonesian language interference that occurs in Thai students while practicing PPL courses at Hasyim Asy'ari University. This research method uses qualitative methods with data collection techniques using observation techniques, audio visual recording techniques using CCTV in the practice room, and note taking techniques. To get the data validity researchers used data triangulation, increased diligence and peer examination through discussion. The data analysis process is data collection, data reduction, data presentation, and conclusions. Most of the speeches of Thai students often occur interference with the phonological system, where they are still carried away by the first language or mother tongue (B1), namely Malay. Interference in the morphological system and in the syntax system can occur because they lack understanding of vocabulary and sentence structure in Indonesian that is good and right.
\end{abstract}

Key Words: Causes, Interference

PENDAHULUAN

Faktor Penyebab Interferensi...| 38 
Bahasa merupakan satu-satunya media yang paling efektif dipakai oleh manusia untuk melakukan komunikasi dengan manusia lain. Bahasa dan manusia merupakan dua hal yang berkaitan dan tidak dapat dipisahkan. Bahasa merupakan hal penting bagi manusia, tanpa bahasa manusia tidak dapat mengutarakan pendapat maupun bertukar pikiran. Bahasa merupakan alat untuk berkomunikasi yang hanya dimiliki oleh manusia. Dalam kehidupan bermasyarakat sebenarnya terdapat alat untuk berkomunikasi selain bahasa, namun nyatanya, bahasa adalah alat yang paling baik dan sempurna dibandingkan dengan alat komunikasi yang lainnya, seperti alat komunikasi pada hewan atau bahasa hewan (Chaer, 2014: 11).

Manusia dapat menyesuaikan bahasa mereka dengan sendirinya. Apabila manusia hidup di dalam lingkungan baru dan memiliki bahasa yang berbeda dengan bahasa ibunya, maka manusia diharuskan menggunakan bahasa yang digunakan dalam lingkungan baru tersebut guna untuk mempermudah manusia berkomunikasi. Biasanya interferensi dapat terjadi dikarenakan penutur menggunakan bahasa kedua (B2), dan yang meyebabkan kesalahan atau interferensi adalah bahasa pertamanya (B1). Sehingga banyak terjadi kesalahan bahasa pada manusia yang hidup di dalam lingkungan baru. Kesalahan bahasa yang terjadi pada manusia biasa disebut denganinterferensi bahasa.

Seperti yang terjadi pada mahasiswa Thailand yang terdapat di Universitas Hasyim Asy'ari Tebuireng Jombang (UNHASY). Mahasiswa dari Thailand sudah terbiasa dengan bahasa keseharian mereka ketika berada di Thailand sehingga terjadi interferensi ketika mereka berpindah ke Indonesia. Terdapat perubahan struktur bahasa yang terjadi saat mahasiswa Thailand ketika sedang berinteraksi dengan mahasiswa lain dari Indonesia. Mahasiswa Thailand merasa sedikit asing dengan bahasa Indonesia, ada beberapa kata yang belum mereka ketahui sehingga mereka menggunakan bahasa asal mereka untuk mengganti kata bahasa Indonesia yang belum diketahui.

Misalnya, pada saat mata kuliah Praktik Pengalaman Lapangan (PPL) yang harus ditempuh oleh semua mahasiswa di jurusan Ilmu Pendidikan, tidak terkecuali juga untuk mahasiswa yang berasal dari Thailand. Sebelum pelaksanaan PPL ke sekolah, mahasiswa terlebih dahulu melakukan praktik simulasi mengajar di kampus atau disebut dengan PPL Dasar.. Pada saat pelaksanaan PPL dasar, mahasiswa dibimbing dosen untuk luwes ketika mengajar dan bertemu langsung dengan siswa di sekolah.

Ketika proses praktik belajar mengajar tersebut berlangsung maka mahasiswa Thailand bisa berprofesi sebagai pendidik maupun sebagai peserta didik. PPL dasar adalah matakuliah yang mengedepankan praktik agar mahasiswa dapat mengajar layaknya seorang guru profesional. PPL dasar hanya terdapat pada jurusan yang berhubungan dengan pendidikan. Berdasarkan pemaparan tersebut maka penelitian ini akan membahas tentang "Faktor penyebab Interferensi Bahasa Indonesia Tuturan Mahasiswa Thailand pada Pembelajaran PPL Dasar di Universitas Hasyim Asy'ari”.

Interferensi menurut Weinreich (Chaer, 2014: 120) mengemukakan bahwa terdapat perubahan sebuah sistem dalam bahasa yang berkaitan dengan terjadinya persentuhan bahasa lain dengan bahasa yang digunakan saat itu. Terjadinya persentuhan bahasa tersebut dilakukan oleh penutur 
bilingual. Makna penutur bilingual adalah penutur yang menggunkan dua bahasa secara bergantian, kedua bahasa tersebut sama-sama dikuasai oleh penutur. Penutur multilingual memiliki makna penutur yang telah memahami atau menguasi berbagai macam bahasa dan di pergunakan secara bergantian.

Penutur biasanya lebih menguasai bahasa pertamanya yaitu bahas ibu (B1). Ketika penutur mempelajari bahasa kedua (B2), mereka akan menemukan istilah yang berbeda dengan bahasa ibunya. Sehingga kosa kata yang mereka pahami tidak cukup banyak. Sehingga ketika seorang penutur melakukan interaksi dengan menggunakan bahasa keduanya (B2), dapat terjadi perubahan sistem dalam bahasa. Sebab penutur lebih menguasai B1 dari pada B2.

Kemampuan setiap penutur terhadap bahasa ibu atau bahasa pertama (B1) dan bahasa kedua (B2) sangat bermacam-macam. Ada seorang penutur yang menguasai bahasa ibu atau bahasa pertama (B1) dan bahasa kedua (B2) sama-sama baiknya maka, penutur tersebut dapat dinamakan penutur berkemampuan bahasa sejajar. Penutur sejajar tentu tidak memiliki kesulitan atau pun masalah ketika ia menggunakan kedua bahasa tersebut. Kedua bahasa tersebut tidak akan saling mempengaruhi karena dapat bekerja sendiri-sendiri. Sedangkan penutur yang dapat menguasai bahasa ibunya atau bahasa pertama (B1) dengan baik, tetapi pada bahasa keduanya (B2) kurang atau minim dikuasai. Penutur ini disebut dengan penutur berkemampuan bahasa majemuk. Tentunya seorang penutur akan merasa kesulitan saat melakukan interaksi dengan orang yang menggunakan bahasa kedua (B2).

Menurut Weinreich (Chaer, 2014: 122) dalam bukunya yang berjudul Language in Contact, ia mengatakan bahwa interferensi adalah kesalahan atau inteferensi bahasa yang terdapat dalam perubahan sistem suatu bahasa, baik mengenai tentang sistem morfologi, baik mengenai tentang sistem fonologi, maupun sistem yang lain. Dalam Bahasa Indonesia banyak terjadi interferensi pada sistem fonologi. Misalnya, orang Indonesia yang berasal dari Jawa, mereka sering menambahkan bunyi nasal di depan kata-kata yang di mulai dengan konsonan /j/, /g/, /d/, dan /b/. Misalnya pada kata [Bandung] menjadi [mBandung], kata [Depok] menjadi [nDepok] dan kata [Jambi] menjadi [nyJambi]. Interferensi juga terjadi pada penutur dari Bali yang mengucapkan fonem /t/ menjadi apikoal veolar retrofleks [t], contoh pada kata-kata [topi], [tangan], [tatang], dan [tinju].

Interferensi dalam sistem fonologi tidak hanya terdapat dalam bahasa Jawa saja, namun dapat terjadi pula pada bahasa-bahasa yang lain. Seperti pada bahasa orang yang yang berasal dari Malaysia yang kemudian datang ke Indonesia. Mereka telah terbiasa menggunakan bahasa Melayu. Misalnya pada kata [saya], orang yang berasal dari Indonesia asli akan mengucapkan kata [saya] akan tetap menjadi [saya] namun, orang pendatang dari Malaysia yang terbiasa menggunakan bahasa Melayu akan terbiasa mengucapkan kata [saya] menjadi [saye].

Interferensi terjadi juga dalam bidang morfologi, antara lain, terdapat pada afiks-afiks atau imbuhan yang bisa berada pada awal atau akhir kata. Afiksafiks ini dipergunakan untuk membentu kosa kata baru di dalam bahasa lain. Misalnya yang terjadi dalam bahasa Belanda dan bahasa Inggris terdapat sufiks-sasi. Maka banyak bahasa Indonesia memamkainya seperti contoh tendanisasi, neonisasi dan turinisasi. Penggunaan bentuk suatu kata seperti 
kemahalan, kekecilan dan ketabrak jika dimasukkan kedalam bahasa baku maka kata-kata tersebut termasuk ke dalam interferensi. Sebab imbuhan yang dipakai berasal dari Jawa. Bentuk baku dari kata berikut adalah terlalu mahal, terlalu kecil, dan tertabrak.

Interferensi bahasa Indonesia dalam sistem morfologi dapat pula terjadi pada bahasa Melayu. Bahasa Melayu banyak digunakan di berbagai negara seperti Malaysia dan Thailand. Mengingat bahwa terdapat sedikit kemiripan dalam bahasa Melayu dengan bahasa Indonesia. Namun, terdapat pula perbedaannya. Seseorang yang berasal dari Malaysia atau Thailand yang berpindah tempat ke Indonesia tentu memiliki perbedaan bahasa khususnya pada sistem morfologi. Orang Malaysia atau Thailand akan terbiasa menggunakan bahasa Melayu sehingga dapat ditemui beberapa interferensi yang terjadi dalam percakapan seharihari mereka. Misalnya pada kata [pohon] dalam bahasa Indonesia, maka orang yang terbiasa menggunakan bahasa Melayu akan mengucapkan kata [pohon] menjadi kata [pokok].

Interferensi di dalam bidang sintaksis, misalnya pada contoh berikut, dalam bahasa Indonesia yang berasal dari bilingual Jawa - Indonesia yang berbahasa Indonesia. Bunyi kalimatnya "Disini ruang paling ramai yang dingin sendiri". Kalimat tersebut merupakan bahasa Indonesia naming menggunakan struktur bahasa Jawa, dalam bahasa Jawab kalimat tersebut berbunyi "Neng kene panggon rame sing adem dhewe". Kata 'Dhewe' pada kalimat tersebut bermakna 'Sendiri'. Misalnya pada contoh lain seperti pada kalimat "Aku dhewe sing moco" (saya sendiri yang membaca), dan pada kalimat "Kowe gowo dewe?" (apakah kamu membawanya sendiri?). Tetapi pada contoh kalimat pertama kata 'Dhewe' yang terletak di antara kata 'sing' dan adjektif memiliki makna 'paling', seperti pada kata sing gedhe dhewe 'yang paling besar', dan sing putih dhewe 'yang paling putih'. Oleh karena itu, dalam bahasa Indonesia yang baik dan benar akan berbunyi "Tempat ramai adalah tempat yang paling dingin disini".

Interferensi terjadi karena terdapat beberapa sebab. Menurut Weinriech (Maryana 2011: 19) interferensi dapat terjadi karena beberapa alasan yaitu: (1) Kedwibahasaan pada penutur, (2) Kebiasaan dalam menggunakan bahasa pertama atau bahasa ibu (B1), dan (3) kurangnya kosa kata baru yang diperoleh.

Penyebab pertama yaitu kedwibahasaan pada penutur dapat terjadi karena adanya kontak dan persentuhan bahasa satu dengan bahasa lain. Penyebab kedua yaitu kebiasaan dalam menggunakan bahasa pertamnya (B1) dapat terjadi saat penutur terbiasa menggunakan bahasa pertama yang diperolehnya. Sehingga panutur dapat melakukan interferensi ketika berinteraksi dengan lawan bicara yang menggunakan B2. Penyebab yang ketiga yaitu kurangnya kosa kata baru, hal ini merupakan penyebab paling banyak ditemui dalam proses belajar. Hal ini dikarenakan banyaknya kosa kata baru yang dipelajari sehingga dalam keterbatasan pemahaman dapat menyebabkan interferensi yang dilakukan oleh penutur.

Penelitian ini berfokus untuk mengetahui penyebab apa saja yang dialami mahasiswa saat menuturkan Bahasa Indonesia.

\section{METODE PENELITIAN}


Jenis penelitian yang dipakai adalah penelitian kualitatif dengan menggunakan model penelitian deskriptif. Metode penelitian kualitatif adalah penelitian yang berhubungan dengan keadaan dan hubungan sosial yang bisa disebabkan oleh banyaknya ragam dalam dunia yang sesungguhnya atau nyata. Sugiyono (2010: 15) berpendapat bahwa penelitian kualitatif merupakan suatu jenis penelitian yang dapat digunakan sebagai peneliti yang akan meneliti pada konteks alamiah dimana peneliti difungsikan sebagai instrument kunci.

Penelitian ini memiliki tujuan untuk memahami fenomena-fenomena yang terjadi dalam suatu penelitian, difikirkan secara menyeluruh, serta menggunakan pengambilan datanya menggunakan teknik deskripsi dalam tataran bahasa dan kata-kata, tentunya dalam suatu konteks khusus dan terjadi secara alamiah (Moleong, 2014: 6). Oleh karena itu, penelitian ini menghasilkan data berupa faktor penyebab terjadinya interferensi bahasa Indonesia pada tuturan mahasiswa Thailand.

Subjek yang dipakai dalam penelitian ini adalah tuturan mahasiswa Thailand semester 5 program studi Bahasa Inggris yang diindikasi sebagai penutur interferensi. Teknik pengumpulan data yang berikutnya adalah teknik rekaman. Teknik rekam digunakan oleh peneliti untuk merekam semua proses pembelajaran yang berlangsung. Alat bantu untuk merekam yang digunakan oleh peneliti hanyalah kamera Sigle Lens Reflex (SLR). Peneliti menggunakan teknik ini agar mempermudah peneliti dalam mengumpulkan data, memudahkan peneliti agar tetap ingat pada konteks yang melatar belakangi tuturan, dan memudahkan peneliti untuk menganalisis data yang telah terkumpul. Setelah proses pengumpulan data tuturan berhasil dikumpulkan, maka langkah berikutnya adalah mencari penyebab terjadinya interferensi. Penyebab interferensi hanya bisa diperoleh dari penutur. Maka teknik yang sesuai untuk mencari penyebab terjadinya interferensi adalah dengan menggunakan teknik wawancara. Wawancara dilakukan guna untuk mengetahui ungkapan atau opini penutur tentang penyebab terjadinya interferensi yang dilakukan oleh penutur.

\section{PEMBAHASAN}

Terjadinya interferensi (kesalahan berbahasa) pada mahasiswa Thailand ketika melakukan praktik mengajar di dalam kelas PPL Dasar tidak menutup kemungkinan memiliki beberapa penyebab. Pada penelitian ini megambil sebuah teori yang mana di dalamnya terdapat beberapa jenis penyebab terjadinya interferensi. Menurut Weinriech (Maryana 2011: 19) interferensi dapat terjadi karena kedwibahasaan pada penutur, kebiasaan dalam menggunakan bahasa ibu atau B1, dan kurangnya pemahaman kosa kata bahasa yang baru di dapatkan. Berdasarkan data yang telah terkumpul, mahasiswa Thailand telah tinggal di negara Indonesia selama kurang lebih dua tahun. Mereka datang ke Indonesia pada tahun 2017. Menurut data yang telah didapatkan sebelum mereka pergi ke Indonesia, mereka tidak melakukan tes berbahasa Indonesia sebelumnya. Mereka mempelajari bahasa Indonesia saat telah sampai di mana tempat ia tinggal di Indonesia. Bahkan, awalnya mereka menggunakan bahasa isyarat sebagai alat berkomunikasi.

Berdasarkan hasil analisis data yang telah diperoleh, maka dapat teridentifikasi penyebab terjadinya interferensi bahasa Indonesia pada mahasiswa Thailand saat melakukan 
praktik mengajar di dalam kelas PPL Dasar. Mahasiswa Thailand memiliki alasan melakukan interferensi dalam bidang fonologi adalah terbiasanya mereka menggunakan bahasa pertama atau bahasa ibu (B1) yaitu bahasa Melayu. Dalam bahasa Melayu memang kata yang berakhiran dengan huruf "a" akan dibaca dengan akhiran huruf "e". Hal tersebut yang menjadi penyebab mahasiswa Thailand sering mengatakan kata yang berakhiran huruf "a" menjadi "e". Tidak hanya pada kata yang berakhiran huruf "a" saja, namun mereka juga sering menggunakan kata yang terdapat huruf " $\mathrm{t}$ " pada awal, tengah atau pada akhir kata. Dalam tuturan mahasiswa Thailand, huruf " $\mathrm{t}$ " diucapkan sebagai huruf "th".

Inteferensi pada sistem morfologi atau kesalahan pada penggunaan kata yang terjadi pada tuturan mahasiswa Thailand, mereka mengatakan bahwa kurang memahami kosa kata dalam bahasa Indonesia. Ketika mereka tidak mengerti kata apa yang harus mereka katakan, maka mereka menggunakan kata dalam bahasa Melayu yang mereka ketahui. Mereka beranggapan bahwa kosa kata dalam bahasa Indonesia dengan bahasa Melayu memiliki kemiripan. Mahasiswa Thailand masih banyak melakukan interferensi pada kata dalam bahasa Indonesia dalam segi afiksasi atau kata yang berimbuhan. Kata dalam bahasa Melayu jarang dibubuhi dengan afiks. Sedangkan dalam bahasa Indonesia pembubuhan afiks sangat diperlukan dalam sebuah kata untuk membangun sebuah makna. Hal ini juga bisa dikatakan bahwa mahasiswa Thailand masih terbawa kebiasaan bahasa pertama atau bahasa Melayu. Dalam situasi ini juga terjadi pada tuturan mahasiswa Thailand ketika mahasiswa Thailand melakukan praktik mengajar di dalam kelas yang mana di dalamnya terdapat interferensi dalam sistem sintaksis atau kesalahan pada susunan kalimat. Mereka kurang memahami bagaimana menyusun kalimat bahasa Indonesia dengan baik. Sehingga susunan kalimat yang mereka gunakan kurang sesuai dengan kaidah bahasa Indonesia.

Menurut pendapat mereka bahasa Indonesia dengan bahasa Melayu memiliki banyak kemiripan. Tanpa mereka sadari mereka berbicara menggunakan susunan bahasa Melayu. Di samping itu, mereka juga tinggal di daerah Jawa. Secara tidak langsung mereka mendapatkan bahasa kedua (B2) dari orang yang berasal dari Jawa. Sehingga susunan kata yang mereka gunakan saat berbicara adalah susunan bahasa Jawa. Nugraheni dan Syuhda, (2019: 13) menyatakan bahwa seorang mahasiswa yang berasal dari negara yang kesehariannya menggunakan bahasa Melayu sering menggunakan bahasa Melayu secara bersamaan dengan bahasa Indonesia hal ini berhubungan dengan bahasa yang mereka hadapi. Susunan kalimat yang mereka gunakan selama berbicara ketika praktik mengajar di dalam kelas hanya berdasarkan sepengetahuan mereka saja. Tanpa menggunakan kaidah berbahasa Indonesia yang baik dan benar.

\section{SIMPULAN}

Berdasarkan hasil penelitian dan pembahasan didapatkan simpulan bahwa beberapa faktor penyebab terjadinya interferensi yaitu, kebanyakan pada tuturan mahasiswa Thailand sering terjadi interferensi pada sistem fonologi, dimana mereka masih terbawa oleh bahasa pertama atau bahasa ibu (B1) yaitu bahasa Melayu. Interferensi pada sistem morfologi serta pada sistem sintaksis dapat terjadi karena mereka kurang memahami kosa 
kata dan susunan kalimat pada bahasa Indonesia yang baik dan benar.

\section{DAFTAR PUSTAKA}

Chaer dan Agustina. 2014.

Sosiolinguistik: Perkenalan Awal. Jakarta: PT. Rineka Cipta

Mariyana, Lisna. 2011. "Interferensi Leksikal Bahasa Indonesia dalam Bahasa Jawa pada Teks Berita Pawartos Jawi Tengah di Cakra Semarang TV". Dalam https://scolar.google.co.id/scola $\underline{r}$ ?hl=id\&as $s d t=0 \% 2 C 5 \& q=i n t e r f$ erensi+leksikal+bahasa+indonesi $a \& b \operatorname{tn} G=\# d=g s$ qabs\&u=\%23p\% 3DKelXXs --qwI. 20 Oktober.

Sugiyono, 2016. Metode Penelitian Kuantitatif, Kualitatif, dan $R \& D$.Bandung: Alfabeta

Nugraheni dan Syuhda. 2019. "Interferensi Bahasa Melayu terhadap Bahasa Indonesia " 13(1). Dalam https://dx.doi.org/10.24036/ld.v 13i1.31974. 011-025. 